\title{
The Impact of Socio-economic Factors on Fertility Behaviour: A Cross-country Analysis
}

\begin{abstract}
REHANA SIDDIQUI
International comparisons of fertility behaviour are based on two crucial assumptions. First, it is assumed that the response of fertility rates to socio-economic factors is similar across different age-cohorts of female population in the reproductive age-group. Second, it is assumed that country-specific effects do not influence the parameter estimates of the fertility model. Recent availability of cross-country data for a number of years allows us to pool data for more than 100 countries for the period 1955-1985 and estimate the fertility model. The results show that the impact of socio-economic factors differs across different age-cohorts; particularly, the negative impact of improvements in female status on the fertility rates is higher among the younger age-cohorts. Similarly, our results show that cross-country differences affect fertility rates significantly. However, the differences tend to diminish as countries become more developed. These results indicate that not only cross-country differences but also the changes in age-composition of female population should be taken into account in formulating the policies to control fertility and population growth. Furthermore, improvements in female literacy turn out to be the most effective tool to control population growth.
\end{abstract}

\section{INTRODUCTION}

The process of demographic transition explains the changes in fertility and mortality as societies develop. ${ }^{1}$ Existing evidence shows that fertility rates have declined sharply after 1970 in the less developed countries (LDCs), whereas rapid decline in mortality rates was observed after the 1950s. This temporal lag between decline in fertility rates and mortality rates has not only changed the size of population, it has also changed the age-distribution of male and female population across countries. These changes in the age distribution of female population are expected to influence the average fertility rates. The existing empirical literature ignores the impact of the changing age-structure of female population on fertility rates. Increase in female population in younger-age cohorts may increase fertility rate. However, the impact

Rehana Siddiqui is Senior Research Economist at the Pakistan Institute of Development Economics, Islamabad.

Author's Note: I wish to express my gratitude to Professor Syed Nawab Haider Naqvi for his invaluable help and encouragement. Thanks are also due the referees for their useful comments. Special thanks are given here to Mr Muhammad Sarwar for typing various drafts of this paper. Any errors and omissions are solely the responsibility of the author.

${ }^{1}$ Coale (1984) defines demographic transition as a “...set of changes in reproductive behaviour that are experienced as a society is transformed from a traditional pre-industrial state to a highly developed, modernised structure”. 
could be negative if economic activity and female status, particularly female education and female labour force participation, improve among the younger females.

The fertility rates also vary across countries. Table A-1 (in Appendix) shows that, on average, general fertility rates (GFR) and infant mortality rates (Inf.) are the highest in low-income countries. Assuming that higher GDP-per capita and/or lower share of agricultural labour force in total labour force are an index of economic development, we can argue that both general fertility rate (GFR) and infant mortality rate (Inf.) decline with economic development. Similarly, GFR and Inf. are higher where social indicators like literacy and availability of health services are low. ${ }^{2}$ Friedlander and Silver (1967) show that while the effect of income on fertility behaviour varies with the level of economic development, the impact of infant mortality and illiteracy is usually positive. ${ }^{3}$ Easterlin (1962 and 1975) shows that growth of female education has the most pervasive influence on the fertility behaviour. Similarly, Chamratrithirong et al. (1992) argue that an increase in female participation in education and employment contributes to a decline in fertility. However, Freedman (1995) claims that in addition to socio-economic development, changes in attitudes about family planning and life-styles and cultural differences affect fertility behaviour significantly. All the existing cross-country studies, analysing fertility behaviour, are based on two crucial assumptions. ${ }^{4}$ First, even if the fertility rates differ across agecohorts of female population in the reproductive age-group, the impact of socioeconomic factors on fertility rates is similar for all age-cohorts. This may not be true as the status of female population may change with changes in the age distribution of female population and consequently the cohort-specific fertility rates may respond differently to these changes in female status. Secondly, it is assumed that the countryspecific factors do not influence the parameter estimates of the fertility model. This assumption may not be valid. For example, Freedman (1995) argues that ideological and cultural differences also influence fertility behaviour. ${ }^{5}$ Therefore, disregard of country-specific effects may lead to biased estimated coefficients of fertility models.

In this study our objective is to test the validity of these assumptions. First, we examine whether or not the impact of socio-economic factors on fertility rates varies

\footnotetext{
${ }^{2}$ Among the numerous empirical studies, the following provide excellent summaries of present and past studies: Adelman (1963); Chamratrithirong et al. (1992); Coale and Hoover (1958); Cochrane (1983); Drakatos (1969); Easterlin (1975); Friedlander and Silver (1967); Schultz (1973); Simon (1974); Ubaid-urRub (1990) and Wheeler (1980).

${ }^{3}$ Friedlander and Silver (1967) argue that either the changes in preference or changes in quantityquality trade-off for children may be responsible for the changing fertility behaviour with the level of economic development.

${ }^{4}$ The study by Wheeler (1980) is the only exception. He examines the differences in fertility behaviour across age-cohorts. However, the study is based on data for the years 1960 and 1977 only.

${ }^{5}$ Similarly, empirical studies in other research areas show significant cross-country differences. For example, Barro (1991) shows that country-specific factors influence growth performance significantly.
} 
across different age-cohorts of female population in the reproductive age-group. Second, we test whether the country-specific effects influence the parameter estimates of the fertility model significantly. Recent availability of cross-country data on fertility rates and other related variables, for different time-periods, allows us to examine these issues. ${ }^{6}$ The results of the study may enable us to draw more appropriate and meaningful inferences about bringing down fertility and population growth rates.

The study has three main sections. A theoretical and empirical specification of the fertility model and data related-issues are discussed in Section I. The results are presented in Section II. The conclusions and policy implications of the analysis are described in the final section.

\section{MODEL SPECIFICATIONS AND DATA PROBLEMS}

\section{Model Specification}

It is an established fact that fertility is determined by biological factors, both economic and non-economic. Empirical studies often assume that the impact of changes in socio-economic conditions on fertility rates is similar across different age-cohorts of female population in the reproductive age-group. In order to examine the impact of changes in age-distribution of the female population, general fertility rate (GFR) is selected as a dependent variable. This variable is considered to be a more refined measure of fertility. ${ }^{7}$ We define the general fertility rate (GFR) as a weighted sum of age-specific fertility rates:

$$
F_{t}=f_{1 t}\left(w_{1 t} / w_{t}\right)+f_{2 t}\left(w_{2 t} / w_{t}\right)+\ldots .+f_{R t}\left(w_{R t} / w_{t}\right) \quad \ldots \quad \ldots
$$

where

$$
\begin{aligned}
F_{t} & =\text { General fertility rate at time ' } t \text { '. } \\
f_{r t} & =\text { Fertility rate of the } r \text { th female age-cohort. } \\
w_{r t} & =\text { Female population in the } r \text { th age group. } \\
w_{t} & =\text { Total female population in the reproductive age group (15-49 years). }
\end{aligned}
$$

Assuming that fertility rate in each age-cohort responds to a set of socioeconomic variables- $X$, and the marginal effect of ' $X$ ' differs across cohorts, we can write:

$$
f_{r t}=a_{r 0}+\sum_{j=1}^{R} a_{r j} \quad X_{t j}+u_{r} \quad \begin{gathered}
r=1, \ldots \ldots, R \\
j=1, \ldots \ldots, k
\end{gathered}
$$

${ }^{6}$ The data for 112-121 countries are pooled for the period 1960-85. The time-period is divided in five five-year annual averages for 1960-65, 1965-70, 1970-75, 1975-80, and 1980-85. The main data sources are: Keyfitz and Flaeger (1990); Summers and Heston (1988); and World Bank (Various Issues).

${ }^{7}$ See Campbell (1983), p. 4. 
where

$f_{i}=$ general fertility rate in the $r$ th age cohort, $\operatorname{arj}=$ parameters; $u r=$ random, (additive) error term. ${ }^{8}$ The set of socio-economic variables $(X)$ includes income, infant mortality rate, female literacy, urbanisation, young dependency, and indicator of family planning (FPL). ${ }^{9,10}$ The rationale for the inclusion of these variables and their expected relationship with the dependent variable are discussed below.

\section{Income}

Existing literature suggests that income per capita, an indicator of economic development, is an important correlate of fertility. Both Malthus and Ricardo argued that improvements in income lead to higher fertility [for a list of studies, see footnote 2]. ${ }^{11}$ Classical economists emphasised that, ignoring the scale effects, the causal relationship between income and fertility is expected to be positive in the short run and it could be negative in the long run. However, in Simon's (1974) study, income is incorporated as a social control variable. The study indicates that income can be used as an effective instrument for lowering fertility. Similarly, Bulatao and Lee (1983) argue that if the increase in income is a result of the increase in the value of time, then fertility rates and income would be negatively correlated.

Therefore, the rise in economic activity may depress current demand for children if economic development is positively correlated with the opportunity cost of time spent for raising children. However, the effect may be different at different stages of economic development [see Friedlander and Silver (1967) and Bulatao and Lee (1983)]. Furthermore, the evidence for the HICs suggests that if the initial fertility rates are very low, the rise in income may have a positive effect on the demand for children [see Bulatao and Lee (1983)]. In order to capture the non-linear effect of income, either squared of income per capita or natural logarithm of income is added in Equation $2 .^{12}$

\footnotetext{
${ }^{8}$ In this study we divide the relevant female population in the following three reproductive agegroups: (i) females 15-25 years old; (ii) females 26-35 years old; and (iii) females 36-49 years old.

${ }^{9} \mathrm{~A}$ number of other variables can be included in the set $X$. For example, age at marriage, social mobility, migration, ethnicity, psychological factors, knowledge of birth control methods, inter-generational wealth flows, family structure, and other social and cultural factors may affect GFR. However, data nonavailability does not allow analysing the role of these variables in fertility determination. Similarly, some studies recommend the inclusion of 'nutrition' as a determinant of fertility. However, according to Bulatao and Lee (1983), malnutrition has small physiological impact on fertility.

${ }^{10} \mathrm{FPL}$ and Ft may be determined simultaneously. However, we are not analysing this aspect in the present study which may affect coefficient estimates.

${ }^{11}$ Malthus emphasised the rigid dependence of population growth on the food supply. Similarly, Ricardo suggests that higher income leads to a rise in marriages and higher fertility. But higher fertility leads to surplus labour and, consequently, depressed earnings [see Blaug (1983)].

${ }^{12}$ The effect of income is expected to be stronger if the income distribution also improves with economic growth. However, due to non-availability of cross-country data on income distribution, this variable is not included in the analysis. Some studies include 'land-holding' as a measure of rural income. It is striking that the studies have consistently found fertility to be positively associated with size of landholding. [see Bulatao and Lee (1983)].
} 
On the basis of existing evidence, it is difficult to predict the sign of coefficient of income. However, given the rising opportunity cost of time, we expect a negative relationship between fertility and income.

\section{Infant Mortality Rate}

An increase in infant mortality rate (Inf.) is expected to raise the fertility rate. This is because a higher level of child mortality would require a larger (average) number of births to have been desired as family size. The parents may want to have more children to replace a lost child or to take precaution against probable future child loss.

This variable may also be an indicator of improvements in health-care facilities as modern medical services and public health advances have stimulated a decline in mortality independent of economic growth and social change [see Adelman (1963); Drakatos (1969) and Tafah-Edokat (1992)]. ${ }^{13}$

So far, in developing countries, a substantial part of the rise in population is the result of a long-time lag between the declines in fertility and mortality. Therefore, we include lagged mortality rate in the Equation and expect a positive sign of the coefficient.

\section{Education}

Education, particularly female education, is expected to be strongly correlated with fertility. It directly affects the supply of children, the demand for children, and the regulatory costs of fertility [see Bulatao and Lee (1983)]; Chamratrithirong et al. (1992) and Tafah-Edokat (1992)]. Studies summarised by Cochrane (1983) suggest that the impact of education on fertility is strongly negative at the higher education level [see Balatao and Lee (1983)]. The study shows that in countries like Bangladesh, Dominican Republic, Mexico, Nepal, Pakistan, Peru, Philippines, Colombia, and Sri Lanka, education is a more cost-effective means of reducing fertility than the provision of family planning services. ${ }^{14}$ According to Campbell (1983), for forecasting purposes, education is the best single predictor of fertility decline. The primary school enrolment ratio (female and total) and current female/total literacy rates were included as a proxy for education.

The effect of female literacy on fertility may be different from the effects of male literacy. Male education may have a positive effect on fertility due to improvement of ability to afford children. However, the net effect of literacy on fertility rates could be

${ }^{13}$ GFR and Inf. may be simultaneously determined. Increase in TFR also increases IMR as it deteriorates the health of mother and the quality of child's life.

${ }^{14}$ Cochrane (1988) also reports that in most countries, family planning is the most cost-effective method to reduce fertility. However, this conclusion may change if we include the external and long-run benefits of education. 
negative because of late marriage and/or increase in the opportunity cost of raising children, which results in a trade-off between the quantity and the quality of children. Therefore, we expect a negative correlation between education, represented by female literacy (Fli) and total literacy (Tli), and fertility. ${ }^{15}$

\section{Urbanisation (urb)}

Increase in the proportion of the population living in urban areas can be taken as a measure of urbanisation. The expected relationship between urbanisation and GFR is expected to be negative as both direct and indirect costs of raising children are higher in urban areas [see Easterlin (1975) and Drakatos (1969)]. Moreover, the response to urban living and lifestyle may raise parental aspirations for the quality of children and ultimately result in a lower demand for children. ${ }^{16}$

\section{Dependency}

Dependency ratio (ydep) is defined as the population below 15-years of age relative to the economically active population (15-64 years old). Increase in 'ydep' may have a positive effect on GFR if it reduces the cost of raising an additional child. The effect on GFR could be negative if it reduces the gap between the desired and the actual family size. Therefore, it is difficult to predict the sign of the estimated coefficient.

\section{Family Planning}

The empirical analysis based on survey data shows that family planning programmes $(\mathrm{Fpl})$ are very effective in reducing fertility. Inclusion of this variable in a macro level study is important as it is expected to have a strong direct negative impact on GFR. However, the data on this variable represented by the proportion of females using contraceptives are available for 22 countries only. ${ }^{17}$

\section{Model Specification: Differences across Age-cohorts}

Since data on fertility rates by age-cohort ( $f r$ ) are seldom available across countries, it is difficult to estimate Equation (2) for each group of females separately. Following Wheeler's (1980) methodology, we test for differences in fertility behaviour

${ }^{15}$ Lagged (i.e., 15-years) female enrolment in primary schools was also included as a proxy for female education. However, the variable was dropped due to non-availability for all the sample countries.

${ }^{16}$ Alternatively, Schultz (1973) uses the percentage of males employed in agriculture to measure relative price effects. The population in urban and rural areas may have a different taste for children and knowledge of contraceptives, and this may result in different costs of raising children. Since this cost is expected to be lower in rural areas, an increase in the proportion of rural population is expected to have a positive effect on fertility.

${ }^{17}$ Berselen and Mauldin index of family programme effort is a better variable to be included in the model. However, the index is not available for all countries for the relevant time-period.

${ }^{18}$ For simplicity, ' $t$ '-time subscript is ignored here. 
across age-cohorts. We substitute Equation (2) in Equation (1) and get: ${ }^{18}$

since $w=w_{1}+w_{2}+\ldots . . w_{r}$

$$
\begin{gathered}
F=\left(a_{10}+\sum_{j=1}^{k} a_{12} x+u_{1}\right)\left(w_{1} / w\right)+\left(a_{20}+\sum_{j} a_{22} x_{j}+u_{2}\right)\left(w_{2} / w\right)+\ldots+ \\
\left(a_{r_{0}}+\sum_{j} a_{R_{2}} \quad x_{j}+u_{r}\right) w r / w=a_{10}\left(w_{1} / w\right)+a_{20}\left(w_{2} / w\right)+\ldots \ldots+ \\
a_{r_{0}}\left(w_{r} / w\right)+\sum a_{12}\left(w_{1} / w\right) x_{j}+\sum_{j} a_{22}\left(w_{2} / w\right) x_{j}+\ldots \ldots+ \\
\left.\sum_{j} a_{r j}(w r / w) x_{j}+\left(u_{1} w_{1} / w\right)+\ldots \ldots+u_{R} w r / w\right) \ldots \ldots
\end{gathered}
$$

we can write

$$
w_{R}=w-w_{1}-w_{2}-\ldots . . w_{R-1}
$$

Consequently, Equation (3) can be written as:

where

$$
\begin{aligned}
F= & \left(a_{10}-a_{R 0}\right)\left(w_{1} / w\right)+\left(a_{20}-a_{R 0}\right) w_{2} / w \ldots \ldots+a_{R 0}+\left(a_{10}-a_{R 0}\right) \\
& \left.\left(w_{1} / w\right)+\sum_{j}\left(a_{22}-a_{R 2}\right) w_{2} / w\right) x_{j}+\ldots \ldots+\sum_{j} a_{R 2} x_{j}+e \quad \ldots
\end{aligned}
$$

$$
e=\left[\left(u_{1}-u_{R}\right) w_{1} / w+\ldots \ldots+u_{R}\right]=\sum_{i=1}^{R-1}\left(u_{r}-u_{R}\right)\left(w_{r} / w\right)+u_{R}
$$

This equation allows for differential impact of ' $X$ ' across age-cohorts. In order to test the hypothesis whether fertility behaviour differs across age-cohorts, we need to estimate the following specifications also.

First, assuming that all marginal effects of ' $X$ ' are equal, i.e.,..., $a_{12}=a_{22}=$ $\ldots . . a_{R 2}$, we can rewrite Equation (4) as:

$$
F=\left(a_{10}-a_{R 0}\right) w_{1} / w+\left(a_{20}-a_{R 0}\right) w_{2} / w+\ldots .+a_{R 0}+a_{2} x+e \quad \ldots \quad \ldots
$$

We refer to Equation (4) and Equation (5) as unconstrained and semi-constrained specifications respectively. Equation (5) will help us to determine the extent and significance of structural differences in fertility rates across age-cohorts.

Second, assuming that the autonomous fertility is similar across age-cohorts, i.e.:

$$
a_{10}=a_{20}=\ldots \ldots . .=a_{R 0}
$$

we can write Equation (4) as:

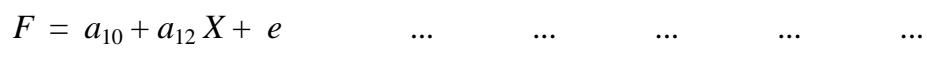

This is called constrained specification, where fertility rate is assumed to be unaffected by changes in age-composition of female population in the reproductive age group. In most empirical studies, Equation (6) is estimated. The comparison of coefficient estimates and $t$-statistics helps us to determine whether fertility behaviour differs across 
age-cohorts or not. Similarly, the F-test determines whether the constrained and unconstrained specifications are different from each other or not.

\section{Model Specification: Cross-country Differences}

In order to test for the presence of country-specific effects, dummy variables are introduced in the model. In this case, the model is modified as:

$$
F_{i t}=\sum_{i=1}^{n} \sum_{r-1}^{R} \alpha_{i} D_{i t}+\sum_{j=2}^{k} \sum_{r-1}^{R} a_{r j} x_{i t j}+U_{i t} \quad \ldots \quad \ldots
$$

where ' $i$ ' denotes the $i$ th country in the sample and $j$ represents $j$ th explanatory variable, the country-specific dummy variables are incorporated in Equations (4), (5), and (6), for estimation. $D_{i t}=1$ if data are for the ith country and $D_{i t}=0$ other wise, and $\alpha_{i}=$ coefficient of country-specific dummy variable. The statistical significance of these coefficients helps to determine the significance of structural differences across countries.

\section{Estimation}

The cross-country data, available for the period 1955-85, is expressed as five years' average. In order to test for the presence of country-specific effects, Ordinary Least Squares (OLS) is not an appropriate technique [see Hsiao (1990)]. Therefore, we conduct Covariance Analysis to examine structural and behavioural differences among different countries. The model is specified as:

$$
F_{t}=\alpha_{0} i+\sum_{j=2}^{k} a_{j i} X_{j i t}+\ldots u_{i t}
$$

where $F_{i t}$ is the general fertility rate, for $i$ th country in the $t$-th time-period, and $x_{j i t}$ are the $j$ th explanatory variables. $U_{i t}$ is the disturbance term. $\alpha_{0}$ and $\alpha j$ are the estimated coefficients. The inclusion of dummy variables will modify the model as following:

$$
F_{i t}=\sum_{i=1}^{n} \sum_{r-1}^{R} a_{0 i} D_{i}+\sum_{j=2}^{k} \sum_{i=2}^{n} a_{k j} x_{j i t}+U_{t} \quad \ldots \quad \ldots
$$

where: otherwise. $^{19}$

$$
D_{i}=\left[d_{i} w_{i} d_{i}\right] ; X_{j}=\left[X_{j} w_{i} X_{j}\right] ; d i=1 \text { if data belongs to the ith country and } d i=0,
$$

The standard $t$-test and $F$-test are applied to see if these alternative specifications

${ }^{19}$ The coefficients of $X_{j}$ may differ across countries also. However, due to problems of degrees of freedom, we do not test for slope differential with respect to all explanatory variables simultaneously. The test for cross-country differences in slope is applied for each explanatory variable in alternative specifications. 
of the fertility model are significantly different from each other or not. In the first case, we test whether or not the marginal effects of fertility determinants vary significantly across age-cohort of female population. For this purpose, the following hypothesis is tested:

$$
\begin{aligned}
& H_{0}: a_{i 2}=a_{j 2} \\
& H_{1}: a_{i 2} \not \equiv a_{j 2}
\end{aligned}
$$

The $t$-statistic of the coefficient of the interactive terms $\left(X_{j} w X_{j}\right)$ will help us to confirm whether the differences across age-cohorts are statistically significant or not. Similarly, $F$-test determines whether the two specification are significantly different or not. The second hypothesis examines whether or not the variation in the current age distribution of female population affects total fertility rate significantly.

That is,

$$
\begin{aligned}
& H_{0}: a_{i 0}=a_{j 0} \\
& H_{i}: a_{i 0} \not \equiv a_{j 0}
\end{aligned}
$$

As mentioned earlier, the $t$-statistics of the coefficients of variables representing age distribution of females (i. e., $w_{r}$ ) determines the statistical significance of the differences. In this case also, $F$-test is applied.

If $H_{0}$ holds in both cases, then we conclude that fertility rates are not statistically different across age cohorts, and the model specified in Equation (6) is relevant. However, if $H_{1}$ holds, then the results of alternative specifications, i.e., Equation (4) and Equation (5), become important.

The third hypothesis is specified to examine whether or not intercepts differ across countries? ${ }^{20}$ Along with the examination of $t$-statistics of the coefficients of dummy variables, the standard $F$-test is applied to test this hypothesis.

In this case:

$$
\begin{aligned}
& H_{0}: \alpha_{01}=\alpha_{02}=\ldots \ldots \ldots \ldots \ldots . . . .=\alpha_{0 n} \\
& H_{1}=\text { the } \alpha_{0 i} \text { are not all equal }
\end{aligned}
$$

and $F$-statistics is:

$$
F_{1}=\frac{\left(\overline{e^{\prime}}-\bar{e}-\hat{e}^{\prime} \hat{e}\right) /(N-1)}{\hat{e}^{\prime} \hat{e} /(N T-N-K)}
$$

where $\bar{e}^{\prime} e^{-}$is the residual sum of square from the restricted model represented by Equation (2); $\hat{e}^{\prime} \hat{e}$ is the residual sum of squares from the unrestricted model represented by Equation (8). ( $N-1)$ is the number of linear restrictions and $(N T-N-K)$ is the degrees of freedom in the unrestricted model. If $F_{1}>F^{*}$, then $H$ o would be rejected. ${ }^{21}$

${ }^{20} \mathrm{~F}$-test is also applied to test for cross-country differences in slope coefficients.

${ }^{21}$ According to Judge et al. (1982), the practice of dropping dummy variables if the coefficient estimates are statistically insignificant should not be encouraged as two different parameterisations of the same problem can lead to different dummy variables being omitted. $F^{*}$ is the table value of $F$-statistics. 


\section{Data Problems}

In this study we have tried to construct consistent cross-country data series for dependent and explanatory variables for more than 100 countries for the years 1955$1985 .^{22}$ The availability and quality of data vary in different parts of the world. The period 1955-85 is divided in five five-year averages. The data on GFRs, female population in different age groups, urbanisation, and infant mortality rate are obtained from Keyfitz and Flaeger (1990). The under-enumeration is widely known with respect to these variables. For example, for Somalia and Zaire, it is reported that the underenumeration is about 25 percent. Similarly for Pakistan, misreporting of young girls is estimated to be equal to 20 percent [See Krotki (1985)]. However, Keyfitz and Flaeger have evaluated and adjusted the data in order to maintain some plausible level of comparability between various regions. General Fertility Rate (GFR) is defined as the annual number of births per 1000 women of child-bearing age. This variable is expected to be sensitive to changes in age-composition of female population. Infant mortality rate is estimated as the number of deaths of children, under age 1, per 1000 children born during the period shown. The reliability of these data, particularly for developing countries, is always questionable.

The income-per capita (GDP-per capita) data series are taken from Summers and Heston (1988). These data, adjusted for purchasing-power parity across countries, are at constant prices of 1980. Despite some measurement and definitional problems, this data set is comparable across countries and over time. However, the data quality indicator reported by Summers and Heston (1988) shows that data quality improves with the development of a country.

The data for total literacy, female literacy, family planning, and labour force in agriculture are taken from the World Bank (various issues). ${ }^{23}$

\section{RESULTS}

\section{Differences across Age-cohorts}

In this section, we first examine the impact of differences in age-cohorts of female population on fertility rates across three different subsets of countries (Equation 4). ${ }^{24}$ The results reported in Table 1 reflect that significant differences exist across different age groups. The coefficients of interactive terms, particularly for female

\footnotetext{
${ }^{22}$ The data after 1985 are based on projections.

${ }^{23}$ The family planning variable is defined as the percentage of married women of child-bearing age using contraceptives, or women whose husbands are practising any form of contraception. Contraceptive usage is generally measured for women aged 15-49. A few countries use measures related to age-group 1544. These data are derived mainly from demographic and health surveys. This statistics may be understated as conventional methods of family planning are not accounted for.

${ }^{24}$ The countries are distributed in three groups on the basis of their per capita GDP in 1970. The per capita GDP in low-income countries was less than \$ 1000; in middle-income countries it was between \$ 1000 and \$ 1500; and in high-income countries the per capita GDP was above \$ 1500 .
} 
Table 1

Determinants of General Fertility Rates: Equation 4

\begin{tabular}{|c|c|c|c|c|c|}
\hline & & All Countries & LICs & MICs & HICs \\
\hline \multirow[t]{2}{*}{$\alpha_{10}$} & & 62.285 & 203.39 & 209.84 & -19.35 \\
\hline & & $(0.79)$ & $(2.26)^{*}$ & $(0.97)$ & $(0.19)$ \\
\hline \multirow{2}{*}{\multicolumn{2}{|c|}{$\operatorname{GDP}\left(\alpha_{11}\right)$}} & 0.003 & -0.156 & 0.030 & 0.002 \\
\hline & & $(0.51)$ & (1.29) & $(0.29)$ & $(0.49)$ \\
\hline \multirow{2}{*}{\multicolumn{2}{|c|}{ Inf. $\left(\alpha_{12}\right)$}} & 0.343 & 0.371 & 0.201 & 0.209 \\
\hline & & $(0.95)$ & $(2.32)^{*}$ & $(1.38)$ & $(0.45)$ \\
\hline \multirow{2}{*}{\multicolumn{2}{|c|}{ flit $\left(\alpha_{13}\right)$}} & -0.358 & -0.064 & -0.113 & -0.366 \\
\hline & & $(0.75)$ & $(0.06)$ & $(0.42)$ & $(2.57)^{*}$ \\
\hline \multirow{2}{*}{\multicolumn{2}{|c|}{ Urb. $\left(\alpha_{14}\right)$}} & -0.488 & -0.059 & 0.299 & -0.090 \\
\hline & & $(1.16)$ & $(1.74)$ & $(0.90)$ & $(0.20)$ \\
\hline \multirow{2}{*}{\multicolumn{2}{|c|}{ Ydep. $\left(\alpha_{15}\right)$}} & 3.489 & 1.15 & 0.986 & 2.521 \\
\hline & & $(4.96)^{*}$ & $(10.04)^{*}$ & $(2.60) *$ & $(3.03) *$ \\
\hline \multirow{2}{*}{\multicolumn{2}{|c|}{ fem1 $\left(\alpha_{20}\right)$}} & 8.072 & -30.01 & 55.28 & 8.428 \\
\hline & & $(2.48)^{*}$ & $(1.43)$ & $(3.70) *$ & $(2.09) *$ \\
\hline \multirow{2}{*}{\multicolumn{2}{|c|}{ fegd $1\left(\alpha_{21}\right)$}} & -0.0002 & 0.007 & -0.012 & -0.0002 \\
\hline & & $(1.13)$ & (1.20) & $(3.14)^{*}$ & $(0.84)$ \\
\hline \multirow{2}{*}{\multicolumn{2}{|c|}{ fein1 $\left(\alpha_{22}\right)$}} & 0.015 & 0.136 & 0.032 & 0.032 \\
\hline & & $(1.09)$ & $(1.96)^{*}$ & $(0.57)$ & (1.89) \\
\hline \multirow{2}{*}{\multicolumn{2}{|c|}{ felt1 $\left(\alpha_{23}\right)$}} & -0.032 & -0.066 & -0.052 & -0.056 \\
\hline & & $(2.88) *$ & $(1.15)$ & $(0.58)$ & $(2.62)^{*}$ \\
\hline \multirow{2}{*}{\multicolumn{2}{|c|}{ feur1 $\left(\alpha_{24}\right)$}} & -0.040 & -0.126 & 0.091 & -0.024 \\
\hline & & $(2.33)^{*}$ & $(0.93)$ & $(0.73)$ & $(1.23)$ \\
\hline \multirow{2}{*}{\multicolumn{2}{|c|}{ feyd $1\left(\alpha_{25}\right)$}} & -0.102 & 0.012 & -0.538 & -0.057 \\
\hline & & $(3.96)^{*}$ & $(0.07)$ & $(3.06)^{*}$ & $(1.82)$ \\
\hline \multirow{2}{*}{\multicolumn{2}{|c|}{ fem2 $\left(\alpha_{30}\right)$}} & -17.08 & -32.95 & -52.72 & -10.152 \\
\hline & & $(3.75)^{*}$ & (1.73) & $(1.74)$ & (1.66) \\
\hline \multirow{2}{*}{\multicolumn{2}{|c|}{ fegd2 $\left(\alpha_{31}\right)$}} & 0.0001 & 0.003 & -0.015 & 0.0001 \\
\hline & & $(0.52)$ & $(0.66)$ & $(2.10)^{*}$ & $(0.28)$ \\
\hline \multirow{2}{*}{\multicolumn{2}{|c|}{ fein2 $\left(\alpha_{32}\right)$}} & 0.063 & 0.095 & 0.230 & 0.048 \\
\hline & & $(2.90)^{*}$ & (1.47) & $(2.72)^{*}$ & $(1.86)$ \\
\hline \multirow{2}{*}{\multicolumn{2}{|c|}{ fefl2 $\left(\alpha_{33}\right)$}} & -0.056 & -0.100 & -0.175 & -0.021 \\
\hline & & $(2.92) *$ & $(2.61)^{*}$ & $(1.07)$ & $(2.51)^{*}$ \\
\hline \multirow{2}{*}{\multicolumn{2}{|c|}{ feur2 $\left(\alpha_{34}\right)$}} & -0.082 & -0.558 & -0.330 & 0.043 \\
\hline & & (3.15)* & $(4.14)^{*}$ & $(1.59)$ & (1.48) \\
\hline \multirow{2}{*}{\multicolumn{2}{|c|}{ feyd2( $\left.a_{35}\right)$}} & 0.060 & 9.123 & 0.188 & 0.057 \\
\hline & & (1.62) & $(0.88)$ & $(2.85)^{*}$ & $(1.26)$ \\
\hline \multicolumn{2}{|l|}{$R^{2}$} & 0.951 & 0.735 & 0.895 & 0.957 \\
\hline \multicolumn{2}{|l|}{$F$} & 688.84 & 37.35 & 29.50 & 361.11 \\
\hline \multicolumn{2}{|l|}{ RMSE } & 13.56 & 12.10 & 12.682 & 12.831 \\
\hline Obs: & & 612 & 246 & 78 & 288 \\
\hline$* t$-statistics & e re] & ported in parentheses. ' *' means & ignificant at & & \\
\hline Notes: GDP & $=$ & Gross Domestic product-per & & & \\
\hline & $=$ & Infant mortality rate. & & & \\
\hline Fli. & $=$ & Female literacy rate. & & & \\
\hline Urb. & $=$ & Urbanisation. & & & \\
\hline Ydep & $=$ & Young dependency. & & & \\
\hline fem 1 & $=$ & proportion of female in the 15 & & & \\
\hline fem 2 & $=$ & proportion of females in 26-35 & & & \\
\hline fe.. & $=$ & $\begin{array}{l}\text { represent different interactive } \\
\text { with each variable described ab }\end{array}$ & proportion of & ation in each & is multiplied \\
\hline
\end{tabular}


literacy (i.e., $\alpha_{23}$ and $\alpha_{33}$ ) and for urbanisation (i.e., $\alpha_{24}$ and $\alpha_{34}$ ), are statistically significant. This means that the response of fertility rates to changes in female literacy and urbanisation differs significantly across age-cohorts. The results show that the negative effect of changes in urbanisation and literacy is strengthened as female population in the younger age-cohorts rises. ${ }^{25}$ The results show that $\alpha$ 's for the excluded category have the expected signs but are mostly insignificant. However, the coefficients for the first two age-cohorts of females show significant differences. This confirms our assertion that it is more informative if we adjust the fertility model for changes in age distribution of female population. Interestingly, the comparison of results reported in Table 1 shows that $\alpha_{20}$ and $\alpha_{30}$ are significantly different from $\alpha_{10}$ in the middle- and high-income groups. This shows that differences in the age distribution of female population do not affect fertility behaviour in the low-income countries, but as the income level goes up, structural differences across younger age cohorts become prominent.

Similarly, fertility behaviour across age-cohorts responds differently to changes in socio-economic factors. For example, for the older-age cohorts' income (GDP) has a positive but statistically insignificant impact on fertility rate in the middle- and highincome countries, and this relationship is statistically insignificant for low-income countries. For the younger age cohorts, the income effect is negative and significant for the middle-income countries, while for the low-income countries the income effect is positive but statistically insignificant. This shows that income effect changes significantly with the level of economic development and across age-cohorts. This could be due to differences in preferences for the quantity and quality of children in developing and developed countries [see Friedlander and Silver (1967)].

The impact of infant mortality (inf.) is, as expected, positive and statistically significant in most cases. The reason may be that provision of improved and better health facilities which leads to a decrease in infant mortality rate may also result in lower fertility rates. Female literacy (fli.) has a negative and statistically significant impact on fertility rate. It appears that opportunity cost plays an important role in the determination of fertility rates in almost all countries. We may, however, note that the sign of the coefficient for the middle-income countries is statistically insignificant in most cases. ${ }^{26}$ This is an unexpected result, and it is not interpreted because of its insignificance. In most cases, the marginal decline in fertility in response to an increase in female literacy is higher in high-income countries and it is higher for females in the

\footnotetext{
${ }^{25}$ In order to test this hypothesis, female population is divided in three reproductive age groups, i.e., female population in age group 15-25 years, 26-35 years, and 36-49 years. In some countries, females in the age group 15-44 are considered a part of females in the reproductive age group. However, for consistency, we include $15-49$ as the relevant group.

${ }^{26}$ According to Adelman (1963), the positive effect may be a reflection of non-linearities in the relationship between fertility and education. Since the coefficient is statistically insignificant, we are not testing for the presence of non-linearities in this paper.
} 
older age group. This is in conformity with the notion that the opportunity cost of having a child is higher in the HICs as compared to that in the LICs. Furthermore, due to human capital accumulation, the opportunity cost of having an additional child is higher for older age groups.

The negative effect of urbanisation (urb.) is statistically significant for the lowand middle-income countries. Furthermore, the impact is higher for the younger age group. The reason may be that urbanisation is expected to be rapid in its initial stages in developing countries. Therefore, the cost of having an additional child is likely to rise sharply in the LICs; consequently, GFR is expected to decline at a faster rate.

Lagged young dependency (ydep) has a positive and statistically significant impact on fertility except for the older age cohort. ${ }^{27}$ The reason may be that the rise in 'ydep' is expected to lower the time cost of raising an additional child, and there may be economies of scale in terms of a lower per child monetary cost of raising an additional child. Interestingly, the marginal impact of ydep on GFR seems to be quite robust across all income groups. However, the interesting results are for the middle-age group, where the impact of young dependency is negative and statistically significant for middle-income countries. The explanation again could be a higher opportunity cost of dependence for the middle-age cohorts. ${ }^{28,29}$

The test for structural differences in fertility behaviour across different agecohorts shows (see Appendix Table A-2) that changes in the age-composition of female population affect fertility rates significantly. It also shows that, on average, fertility rate goes down as the proportion of females in the younger-age cohorts increases. The reason could be that, as discussed earlier, improvement in female status among the younger-age cohorts increases the opportunity cost of having an additional child.

\section{Differences across Countries}

The second hypothesis is whether the country-specific factors affect fertility behaviour significantly or not. ${ }^{30}$ F-test (see Table A-5, row 2) indicates that significant structural differences exist across countries. The results are reported in Table 2 and the coefficients of dummy variables, representing differences among intercept terms for each country, are reported in Table A-4 (in Appendix). Interestingly, the size of the

${ }^{27}$ Young dependency and total fertility rates may be simultaneously determined. However, we are using young dependency-lagged five years. Therefore the issue of simultaneity may not be important.

${ }^{28}$ The results corresponding to Equation 5 and Equation 6 are reported in Appendix Table A-2 and in Appendix Table A-3, respectively. However, the results are not discussed in detail to avoid repetition.

${ }^{29}$ The results of $F$-test (for test of linear restrictions) are reported in Table A-5 (see Appendix). The test also confirms that the two specifications are significantly different from each other.

${ }^{30}$ Due to problems of degree of freedom, multiplicative country-specific dummy variables were not included in one equation. The multiplicative dummy variables, for each variable were included in separate equations. Since the broad conclusions regarding the significance of variables do not change, we do not report them here. However, the results are available with the author. 
Table 2

Determinants of Fertility LSDV Estimates: Equation 4

\begin{tabular}{|c|c|c|c|}
\hline & LICs & MICs & OICs \\
\hline \multirow[t]{2}{*}{$\alpha 10$} & 203.53 & 29.774 & -139.89 \\
\hline & $(2.52) *$ & $(0.08)$ & (1.16) \\
\hline \multirow[t]{2}{*}{$\operatorname{GDP}\left(\alpha_{11}\right)$} & -0.412 & -0.002 & -0.003 \\
\hline & $(4.29)^{*}$ & $(0.02)$ & $(0.52)$ \\
\hline \multirow[t]{2}{*}{ Inf. $\left(\alpha_{12}\right)$} & 0.301 & 0.113 & 0.026 \\
\hline & $(2.37)^{*}$ & $(0.09)$ & $(0.05)$ \\
\hline \multirow[t]{2}{*}{ flit $\left(\alpha_{13}\right)$} & -0.812 & -0.22 & -0.724 \\
\hline & $(2.73)^{*}$ & $(2.95)^{*}$ & $(2.94)^{*}$ \\
\hline \multirow[t]{2}{*}{ Urb. $\left(\alpha_{14}\right)$} & 0.185 & -0.605 & 0.322 \\
\hline & $(0.81)$ & $(2.36)^{*}$ & $(0.63)$ \\
\hline \multirow[t]{2}{*}{ Ydep. $\left(\alpha_{15}\right)$} & 0.601 & 0.512 & 0.434 \\
\hline & $(0.23)$ & (1.92) & $(4.71)^{*}$ \\
\hline \multirow[t]{2}{*}{$\alpha 20$} & -35.142 & 19.576 & 8.223 \\
\hline & $(2.12)^{*}$ & (1.73) & $(1.62)$ \\
\hline \multirow[t]{2}{*}{ fegd1 $\left(\alpha_{21}\right)$} & 0.006 & -0.004 & 0.0001 \\
\hline & (1.65) & $(1.21)$ & $(0.51)$ \\
\hline \multirow[t]{2}{*}{ fein1 $\left(\alpha_{22}\right)$} & 0.15 & 0.055 & 0.002 \\
\hline & $(2.80)^{*}$ & (1.38) & $(0.10)$ \\
\hline \multirow[t]{2}{*}{ felt1 $\left(\alpha_{23}\right)$} & -0.064 & -0.082 & -0.047 \\
\hline & $(2.43)^{*}$ & (1.14) & (1.65) \\
\hline \multirow[t]{2}{*}{ feur1 $\left(\alpha_{24}\right)$} & -0.154 & 0.133 & -0.011 \\
\hline & $(1.57)$ & $(1.41)$ & $(0.40)$ \\
\hline \multirow[t]{2}{*}{ feyd1 $\left(\alpha_{25}\right)$} & 0.068 & -0.205 & -0.112 \\
\hline & $(0.58)$ & (1.58) & $(2.95)^{*}$ \\
\hline \multirow[t]{2}{*}{$\alpha 30$} & -7.45 & -13.986 & -2.218 \\
\hline & $(0.50)$ & $(0.57)$ & $(0.34)$ \\
\hline \multirow[t]{2}{*}{ fegd2( $\left.\alpha_{31}\right)$} & 0.02 & 0.005 & 0.0001 \\
\hline & $(5.21)^{*}$ & $(0.97)$ & $(0.26)^{*}$ \\
\hline \multirow[t]{2}{*}{ fein2 $\left(\alpha_{32}\right)$} & 0.02 & 0.073 & 0.040 \\
\hline & $(0.36)$ & (1.14) & (1.51) \\
\hline \multirow[t]{2}{*}{ fefl2( $\left.\alpha_{33}\right)$} & -0.030 & -0.037 & -0.006 \\
\hline & $(2.56)^{*}$ & $(0.29)$ & $(0.14)$ \\
\hline \multirow[t]{2}{*}{ feur2 $\left(\alpha_{34}\right)$} & 0.08 & 0.168 & 0.019 \\
\hline & $(0.75)$ & (1.17) & $(0.64)$ \\
\hline \multirow[t]{2}{*}{ feyd2( $\left.\alpha_{35}\right)$} & -0.075 & -0.084 & -0.037 \\
\hline & $(0.70)$ & $(0.57)$ & $(0.78)$ \\
\hline$R^{2}$ & 0.917 & 0.971 & 0.972 \\
\hline$F$ & 37.34 & 54.58 & 134.67 \\
\hline RMSE & 7.45 & 7.44 & 11.36 \\
\hline Obs: & 246 & 78 & 288 \\
\hline
\end{tabular}

Note: The coefficients of dummy variables, representing constant differences from ' $\alpha_{0}$ ' are reported in Table A-4. For the explanation of variables, see the note below Table 1. 
estimated coefficients of explanatory variables declines when we try to capture the effect of country-specific factors. The coefficients of country-specific dummy variables are statistically significant for the majority of low-income countries. But the similarities are more prevalent among high-income countries as only 1/4th of the countries show statistically significant differences. This shows that as the countries develop, differences in fertility behaviour tend to diminish. The reason may be that GFR converges in most high-income countries as variations in fertility rates are lower in high-income countries as compared to low-income countries.

The results confirm that female status is the most important variable which is responsible for lowering fertility rates in almost all countries. For the females, in all age groups, income affects fertility negatively and significantly for low-income countries. However, this result contradicts the results reported for the middle income countries. For the middle-age cohorts, income effect is negative but insignificant. In low-income countries, the impact of infant mortality rates on fertility rates remains positive and it is also statistically significant. The impact of female literacy remains strong and negative. This confirms the results of Chamratrithirong et al. (1992) and others that female status is the major factor influencing fertility. The striking result is that, in the high-income countries, the impact of urbanisation is stronger and significant for females in the younger-age cohort. This may be a reflection of the rising cost of living and, consequently, the rising cost of having an additional child in urban areas. Also, young dependency becomes statistically insignificant for all age cohorts in all countries except in the high-income countries.

We have earlier discussed that the major problem in analysing the role of family planning activities is the non-availability of data for most of the countries. However, we have estimated Equation 6 with the "family planning" variable for a limited number of countries. $^{31}$ The results show that in low- and middle-income countries, family planning activities play an active role in reducing fertility rates. However, the effect is negligible in high-income countries. The reason may be that these countries have already reached very low fertility levels and the increase in family planning activities cannot reduce fertility rates any further. However, due to data constraints, this result may be interpreted with caution. ${ }^{32}$

\footnotetext{
${ }^{31}$ The results are available with the author.

${ }^{32}$ Religion may influence the fertility behaviour of individuals. For example, it is sometimes claimed that Muslim countries have higher fertility rates due to religious (Re) considerations. This claim may not be valid considering the recent fall in population growth rates in Malaysia, Indonesia, and Bangladesh. Therefore, we tend to include 'Re' as a control variable in the fertility equation. The factor is specified as a dummy variable equalling one for a Muslim country and zero otherwise to capture the differences in fertility behaviour between the Muslim and non-Muslim countries. The results show little significant influence of Islam on fertility behaviour. (Table available on request.) However, simply controlling for Islam and ignoring the religiosity industry cannot give us the real impact of religion on fertility.
} 


\section{CONCLUSIONS}

Studies of fertility behaviour generally ignore the differences in fertility rates across age-cohorts and the presence of country-specific effects across developing and developed countries. The present study addresses these issues and draws certain conclusions. The results of our study show that fertility behaviour differs significantly across age-cohorts and across countries. It is, therefore, important that these differences should be taken into consideration while formulating specific policies to control population growth.

The study shows that income effect varies significantly across countries. It is negative and statistically significant in low-income countries (LICs) but positive and statistically insignificant in middle- and high-income countries. The result for middleincome countries (MICs) shows a negative income effect for younger-age cohorts. The variable representing female status, i.e., female literacy, shows a consistently negative impact on fertility rates. The impact of urbanisation is negative, while that of 'ydep' is positive for fertility in older-age cohorts. These results show that the rising opportunity cost of having another child affects fertility rates significantly.

The results of this study also confirm the fact that the impact of socio-economic factors differs across age-cohorts. This implies that any policy prescription to control fertility should take into consideration the age-cohorts interaction also.

As expected, our results show that cross-country differences in fertility tend to decline as countries develop. The reason may be that fertility rates in most high-income countries are low and have little variation. The important policy implication derived from this analysis suggests that any intervention to control the population growth should take into consideration the interaction between the female population structure and the socio-economic factors and identify the age groups where fertility rate is more sensitive to socio-economic changes and to the provision of family planning services. This interaction provides useful policy instruments for lowering fertility rates effectively among different age-cohorts. 
Appendices

Table A-1

Mean and Coefficient of Variation of Variables (1960-85)

\begin{tabular}{|c|c|c|c|c|c|c|c|c|}
\hline \multirow[b]{2}{*}{ Var. } & \multicolumn{2}{|c|}{ All Countries } & \multicolumn{2}{|c|}{ LICs } & \multicolumn{2}{|c|}{ MICs } & \multicolumn{2}{|c|}{ HICs } \\
\hline & Mean & C.V. & Mean & C.V. & Mean & C.V. & Mean & C.V. \\
\hline GDP & 3074.050 & 1.349 & 657.435 & 1.322 & 1282.4100 & 0.373 & 5324.69 & 0.910 \\
\hline G & 1.584 & 2.038 & 0.866 & 3.402 & 1.6297 & 1.982 & 2.105 & 1.584 \\
\hline GFR & 162.30 & 0.376 & 201.53 & 0.153 & 187.78 & 0.178 & 120.45 & 0.501 \\
\hline Fli & 74.086 & 0.482 & 45.901 & 0.703 & 80.9460 & 0.307 & 95.021 & 0.248 \\
\hline FEM & 10255.400 & 2.846 & 13181.06 & 3.241 & 5959.3600 & 1.150 & 9053.580 & 1.883 \\
\hline FE1 & 994.900 & 3.000 & 1356.23 & 3.303 & 641.8900 & 1.225 & 803.300 & 1.872 \\
\hline FE2 & 874.650 & 3.010 & 1162.15 & 3.359 & 539.50000 & 1.220 & 735.540 & 0.517 \\
\hline FE3 & 666.251 & 2.915 & 836.947 & 3.358 & 378.4560 & 1.207 & 553.470 & 1.984 \\
\hline Urb & 41.457 & 0.628 & 21.345 & 0.759 & 34.9510 & 0.409 & 58.550 & 2.618 \\
\hline Lif & 55.820 & 0.229 & 44.704 & 0.166 & 54.4770 & 0.171 & 64.714 & 0.147 \\
\hline Inf & 97.628 & 0.617 & 145.316 & 0.259 & 98.7620 & 0.447 & 58.710 & 0.849 \\
\hline Phy & 12083.050 & 1.515 & 25537.54 & 0.880 & 7360.0600 & 1.063 & 2242.320 & 1.928 \\
\hline PN & 3458.120 & 2.091 & 6587.95 & 1.596 & 2386.5100 & 0.675 & 1133.270 & 1.701 \\
\hline $\mathrm{Ag}$ & 47.690 & 0.608 & 74.26 & 0.199 & 52.8380 & 0.328 & 21.390 & 0.835 \\
\hline Ed & 58.020 & 0.544 & 31.92 & 0.606 & 57.3100 & 0.396 & 94.212 & 0.246 \\
\hline
\end{tabular}

Notes: LICs $=$ low-income countries (GDP less than or equal to $\$ 1000$ in 1970).

MICs = middle-income countries, (GDP is between $\$ 1001 \$ 1500$ in 1970).

HICs = high-income countries, (GDP is greater than $\$ 1500$ in 1970)

Var. = variables.

C.V. = coefficient of variation.

GDP = real gross domestic product per capita.

$\mathrm{G}=$ annual average growth rate of GDP.

$\mathrm{GFR}=$ general fertility rate

Fli $=$ female literacy, i.e., percentage of female population enrolled in primary schools lagged 10 years.

$\mathrm{FEM}=$ total female population.

FE1 = female population aged 15-20 years.

FE2 = female population aged $20-25$ years.

FE3 = female population aged $30-35$ years.

Urb $=$ urbanisation.

Lif $=$ life-expectancy at birth.

Inf $=$ infant mortality rate.

Phy $=$ population per physician.

$\mathrm{PN}=$ population per nursing staff.

$\mathrm{Ag}=$ agricultural labour force

$\mathrm{Ed}=$ total literacy 
Table A-2

Determinants of Fertility: Equation 5

\begin{tabular}{lcccc}
\hline & All Countries & LICs & MICs & HICs \\
\hline$\alpha_{0}$ & 53.71 & 105.85 & 20.99 & 62.92 \\
GDP & $(5.70)^{*}$ & $(3.11)^{*}$ & $(0.32)$ & $(5.62)^{*}$ \\
& -0.0002 & 0.006 & -0.003 & -0.0001 \\
Inf. & $(0.38)$ & $(1.31)$ & $(0.53)$ & $(0.26)$ \\
& 0.245 & 0.119 & 0.428 & 0.303 \\
Fli. & $(10.94)^{*}$ & $(3.40)^{*}$ & $(5.96)^{*}$ & $(8.90)^{*}$ \\
& -0.187 & -0.157 & 0.098 & -0.326 \\
Urb. & $(6.47)^{*}$ & $(4.12)^{*}$ & $(0.84)$ & $(6.49)^{*}$ \\
& -0.065 & -0.397 & 0.197 & 0.083 \\
Ydep. & $(1.64)$ & $(4.20)^{*}$ & $(1.16)$ & $(1.67)$ \\
Fem1 & 2.430 & 2.170 & 2.118 & 2.210 \\
& $(40.45)^{*}$ & $(15.92)^{*}$ & $(6.59)^{*}$ & $(26.39)^{*}$ \\
Fem2 & -4.958 & -4.12 & -6.941 & -4.036 \\
$R^{2}$ & $(11.95)^{*}$ & $(4.19)^{*}$ & $(4.56)^{*}$ & $(7.93)^{*}$ \\
F & 1.066 & -0.840 & 4.648 & 0.197 \\
RMSE & $(1.91)$ & $(0.5)$ & $(2.00)^{*}$ & $(0.32)$ \\
Obs. & 0.948 & 0.694 & 0.846 & 0.952 \\
\hline
\end{tabular}

Table A-3

Determinants of Fertility: Equation 6

\begin{tabular}{|c|c|c|c|c|}
\hline & All Countries & LICs & MICs & HICs \\
\hline \multirow[t]{2}{*}{$\overline{\alpha_{0}}$} & 2.17 & 17.001 & -39.46 & 22.828 \\
\hline & $(0.36)$ & (1.33) & (1.51) & $(2.40)^{*}$ \\
\hline \multirow[t]{2}{*}{ GDP } & 0.00002 & 0.003 & -0.012 & -0.0004 \\
\hline & $(0.03)$ & $(0.70)$ & (1.85) & $(0.75)$ \\
\hline \multirow[t]{2}{*}{ Inf. } & 0.278 & 0.132 & 0.544 & 0.343 \\
\hline & $(11.17)^{*}$ & $(3.70)^{*}$ & $(7.15)^{*}$ & $(9.01)^{*}$ \\
\hline \multirow[t]{2}{*}{ Fli. } & -0.186 & -0.139 & 0.151 & -0.369 \\
\hline & $(5.72)^{*}$ & $(3.57)^{*}$ & (1.14) & $(6.52)^{*}$ \\
\hline \multirow[t]{2}{*}{ Urb. } & -0.051 & -0.380 & 0.274 & 0.101 \\
\hline & (1.13) & $(3.90)^{*}$ & (1.42) & $(1.80)$ \\
\hline \multirow[t]{2}{*}{ Ydep. } & 2.042 & 2.174 & 1.883 & 1.793 \\
\hline & $(40.96)^{*}$ & $(20.4)^{*}$ & $(7.26)^{*}$ & $(26.89)^{*}$ \\
\hline$R^{2}$ & 0.934 & 0.670 & 0.788 & 0.938 \\
\hline$F$ & 1716.39 & 97.70 & 52.67 & 866.89 \\
\hline RMSE & 15.686 & 13.17 & 16.421 & 15.12 \\
\hline Obs. & 612 & 246 & 78 & 288 \\
\hline \multicolumn{5}{|c|}{$\begin{array}{l}=\text { Low income countries. } \\
=\text { Middle income countries. } \\
=\text { High income countries. } \\
=\text { Number of observations. }\end{array}$} \\
\hline
\end{tabular}


Table A-4

Country-specific Differences

\begin{tabular}{|c|c|c|c|c|c|}
\hline \multicolumn{2}{|c|}{ LICs } & \multicolumn{2}{|c|}{ MICs } & \multicolumn{2}{|c|}{ HICs } \\
\hline Country & Coefficient & Country & $\overline{\text { Coefficient }}$ & Country & $\overline{\text { Coefficient }}$ \\
\hline Afghanistan & $\begin{array}{r}-16.692 \\
(3.60)^{*}\end{array}$ & Bolivia & $\begin{array}{l}13.354 \\
(2.35)^{*}\end{array}$ & Algeria & $\begin{array}{c}-6.813 \\
(1.03)\end{array}$ \\
\hline Bangladesh & $\begin{array}{c}-32.23 \\
(5.54)^{*}\end{array}$ & Dominican Rep. & $\begin{array}{l}10.399 \\
(1.081)\end{array}$ & Argentina & $\begin{array}{r}-11.558 \\
(1.97)\end{array}$ \\
\hline Benin & $\begin{array}{c}-35.47 \\
(6.57)^{*}\end{array}$ & Ecuador & $\begin{array}{c}5.931 \\
(0.73)\end{array}$ & Australia & $\begin{array}{r}-10.808 \\
(2.15)^{*}\end{array}$ \\
\hline Brundi & $\begin{array}{c}-38.78 \\
(6.98)^{*}\end{array}$ & El Salvador & $\begin{array}{l}11.039 \\
(1.71)\end{array}$ & Belgium & $\begin{array}{l}-8.247 \\
(3.65)^{*}\end{array}$ \\
\hline Burkina Faso & $\begin{array}{c}-30.40 \\
(7.16)^{*}\end{array}$ & Ivory Coast & $\begin{array}{l}30.639 \\
(3.30)^{*}\end{array}$ & Brazil & $\begin{array}{r}-12.606 \\
(1.90)\end{array}$ \\
\hline Burma & $\begin{array}{c}-22.64 \\
(3.66)^{*}\end{array}$ & Jordon & $\begin{array}{l}57.005 \\
(8.51)^{*}\end{array}$ & Canada & $\begin{array}{c}-6.168 \\
(1.01)\end{array}$ \\
\hline Cameroon & $\begin{array}{c}-33.46 \\
(5.48)^{*}\end{array}$ & Korea & $\begin{array}{l}-8.465 \\
(0.92)\end{array}$ & Chile & $\begin{array}{c}-22.66 \\
(3.11)^{*}\end{array}$ \\
\hline Chad & $\begin{array}{c}-21.51 \\
(4.64)^{*}\end{array}$ & Mozambique & $\begin{array}{r}-37.239 \\
(1.84)\end{array}$ & Denmark & $\begin{array}{l}-4.532 \\
(0.87)\end{array}$ \\
\hline Congo & $\begin{array}{r}-22.706 \\
(5.22)^{*}\end{array}$ & Paraguay & $\begin{array}{r}-6.235 \\
(0.48)\end{array}$ & Finland & $\begin{array}{c}3.741 \\
(0.60)\end{array}$ \\
\hline Egypt & $\begin{array}{l}-18.56 \\
(5.08)^{*}\end{array}$ & Philippines & $\begin{array}{c}-3.828 \\
(0.22)\end{array}$ & France & $\begin{array}{c}0.327 \\
(0.05)\end{array}$ \\
\hline Ethiopia & $\begin{array}{c}-25.56 \\
(4.24)^{*}\end{array}$ & Sri Lanka & $\begin{array}{r}-57.258 \\
(2.32)^{*}\end{array}$ & Germany & $\begin{array}{c}-7.620 \\
(1.03)\end{array}$ \\
\hline Ghana & $\begin{array}{c}-41.12 \\
(4.50)^{*}\end{array}$ & Thailand & $\begin{array}{r}-39.713 \\
(1.51)\end{array}$ & Greece & $\begin{array}{l}-9.810 \\
(4.74)^{*}\end{array}$ \\
\hline Guniea & $\begin{array}{c}-18.78 \\
(4.79)^{*}\end{array}$ & & & Guatamala & $\begin{array}{c}7.648 \\
(1.10)\end{array}$ \\
\hline Haiti & $\begin{array}{c}-17.52 \\
(2.95)^{*}\end{array}$ & & & Hong Kong & $\begin{array}{r}-10.000 \\
(1.34)\end{array}$ \\
\hline Honduras & $\begin{array}{c}-11.60 \\
(2.07)^{*}\end{array}$ & & & Iran & $\begin{array}{r}-17.803 \\
(2.43)^{*}\end{array}$ \\
\hline $\begin{array}{l}\text { Central African } \\
\text { Republic }\end{array}$ & $\begin{array}{c}-20.22 \\
(4.68)^{*}\end{array}$ & & & Colombia & $\begin{array}{l}1.550 \\
(0.25)\end{array}$ \\
\hline India & $\begin{array}{l}-12.66 \\
(2.83)^{*}\end{array}$ & & & Costa Rica & $\begin{array}{l}15.056 \\
(2.17)^{*}\end{array}$ \\
\hline Indonesia & $\begin{array}{l}-6.72 \\
(1.50)\end{array}$ & & & Ireland & $\begin{array}{l}1.973 \\
(0.31)\end{array}$ \\
\hline Kenya & $\begin{array}{l}-3.85 \\
(0.93)\end{array}$ & & & Iraq & $\begin{array}{c}3.96 \\
(0.60)\end{array}$ \\
\hline Lesotho & $\begin{array}{l}-8.90 \\
(1.41)\end{array}$ & & & Israel & $\begin{array}{l}-0.084 \\
(0.01)\end{array}$ \\
\hline Liberia & $\begin{array}{c}-18.01 \\
(3.63)^{*}\end{array}$ & & & Jamaica & $\begin{array}{r}-19.327 \\
(2.61)^{*}\end{array}$ \\
\hline
\end{tabular}


Table A-4-(Continued)

\begin{tabular}{|c|c|c|c|c|c|}
\hline \multicolumn{2}{|c|}{ LICs } & \multicolumn{2}{|c|}{ MICs } & \multicolumn{2}{|l|}{ HICs } \\
\hline Country & Coefficient & Country & Coefficient & Country & Coefficient \\
\hline \multirow[t]{2}{*}{ Madagascar } & -21.30 & & & Japan & -4.752 \\
\hline & $(4.18)^{*}$ & & & & $(0.79)$ \\
\hline \multirow{2}{*}{ Malawi } & -17.14 & & & Malaysia & 22.048 \\
\hline & $(4.07)^{*}$ & & & & $(2.77)^{*}$ \\
\hline \multirow[t]{2}{*}{ Mali } & -19.45 & & & Mexico & 3.813 \\
\hline & $(4.88)^{*}$ & & & & $(0.66)$ \\
\hline \multirow[t]{2}{*}{ Morocco } & -11.76 & & & Netherlands & -9.002 \\
\hline & $(2.04)^{*}$ & & & & $(1.56)$ \\
\hline \multirow[t]{2}{*}{ Nepal } & -24.49 & & & Nicaragua & 4.070 \\
\hline & $(5.46)^{*}$ & & & & $(0.65)$ \\
\hline \multirow[t]{2}{*}{ Nigeria } & -13.22 & & & Norway & 9.001 \\
\hline & $(2.17)^{*}$ & & & & (1.43) \\
\hline \multirow[t]{2}{*}{ Niger } & -33.19 & & & New Zealand & -9.283 \\
\hline & $(6.92)^{*}$ & & & & (1.96) \\
\hline \multirow[t]{2}{*}{ Pakistan } & -3.23 & & & Panama & 20.435 \\
\hline & $(0.77)$ & & & & $(3.03)^{*}$ \\
\hline \multirow[t]{2}{*}{ Rwanda } & 1.27 & & & Peru & -6.26 \\
\hline & $(0.22)$ & & & & $(0.89)$ \\
\hline \multirow[t]{2}{*}{ Senegal } & -2.89 & & & Papua New & 7.653 \\
\hline & $(0.67)$ & & & Guinea & $(0.94)$ \\
\hline \multirow[t]{2}{*}{ Sierra Leone } & -3.07 & & & Saudi Arabia & -0.163 \\
\hline & $(0.62)$ & & & & $(0.02)$ \\
\hline \multirow[t]{2}{*}{ Somalia } & -47.57 & & & South Africa & -15.412 \\
\hline & $(8.36)^{*}$ & & & & $(2.18)^{*}$ \\
\hline \multirow[t]{2}{*}{ Sudan } & -41.21 & & & Singapore & -10.838 \\
\hline & $(7.66)^{*}$ & & & & (1.19) \\
\hline \multirow[t]{2}{*}{ Tanzania } & -30.91 & & & Spain & -5.539 \\
\hline & $(5.54)^{*}$ & & & & (1.07) \\
\hline \multirow[t]{2}{*}{ Togo } & 1.54 & & & Switzerland & 13.563 \\
\hline & $(0.96)$ & & & & (1.98) \\
\hline \multirow[t]{2}{*}{ Uganda } & -49.14 & & & Syria & -2.962 \\
\hline & (10.81)* & & & & (1.29) \\
\hline \multirow[t]{2}{*}{ Zaire } & 1.88 & & & Trinidad-Tobago & 8.905 \\
\hline & $(0.43)$ & & & & (1.14) \\
\hline \multirow[t]{8}{*}{ Zambia } & -53.16 & & & Turkey & -31.203 \\
\hline & $(4.29)^{*}$ & & & & $(3.84)^{*}$ \\
\hline & & & & United Kingdom & n $\quad-4.498$ \\
\hline & & & & & $(0.84)$ \\
\hline & & & & Uruguay & -15.79 \\
\hline & & & & & $(2.67)^{*}$ \\
\hline & & & & USA & -5.525 \\
\hline & & & & & $(0.91)$ \\
\hline
\end{tabular}

* The coefficients are statistically significant. 
Table A-5

F-test for Alternative Hypotheses

\begin{tabular}{lcccc}
\hline & All Countries & LICs & MICs & HICs \\
\hline Case A: (Table 1, Table A3) & 19.763 & 5.106 & 5.551 & 11.021 \\
& & & & \\
Case B: (Table 2, Table A3) & - & 10.848 & 11.804 & 2.820 \\
\hline $\begin{array}{l}\text { Notes: Case A: } \alpha_{0} \text { are similar across age cohorts. } \\
\text { Case B: Country-specific effects are not statistically significant. }\end{array}$ & & & \\
& & & \\
& REFERENCES
\end{tabular}

Adelman, I. (1963) An Econometric Analysis of Population Growth. American Economic Review 53:3 314-339.

Barro, R. J. (1991) Economic Growth in a Cross-section of Countries. Quarterly Journal of Economics 106: May 407-43.

Blaug, M. (1983) Economic Theory in Retrospect (3rd Edition). Cambridge: Cambridge University Press.

Bulatao, R. A., and R. D. Lee (1983) Determinants of Fertility in Developing Countries. New York: II: Academic Press, Inc.

Campbell, A. A. (1983) Manual of Fertility Analysis. New York: Churchill Livingston.

Chamratrithirong, A., C. Hirschman and P. Guest (1992) A Multi-level Analysis of the Determinants of Fertility in the Four Regions of Thailand. Asia-Pacific Population Journal 7:1 51-64.

Coale, A. J. (1984) The Demographic Transition. The Pakistan Development Review 23:4 531-552.

Coale, A. J., and E. M. Hoover (1958) Population Growth and Economic Development in Low-income Countries: A Study of India's Prospects. Princeton: Princeton University Press.

Cochrane, S. H. (1983) The Effects of Education, Health, and Social Security on Fertility in Developing Countries. Population and Human Resource Development WPS-53. September. Washington, D. C.: The World Bank.

Drakatos, C. G. (1969) The Determinants of Birth Rate in Developing Countries: An Econometric Study of Greece. Economic Development and Cultural Change 17:4 596-603.

Easterlin, R. (1962) Effects of Population Growth on the Economic Development of Developing Countries. Annals of the American Academy of Political and Social Science 368: 98-108. 
Easterlin, R. (1975) An Economic Framework for Fertility Analysis. Studies in Family Planning 6:3 54-63.

Freedman, R. (1995) Asia's Recent Fertility Decline and Prospects for Future Demographic Change. Asia-Pacific Population Research Reports 1. January.

Friedlander, S., and M. Silver (1967) A Quantitative Study of the Determinants of Fertility Behaviour. Demography 4:1 30-70.

Hsiao, C. (1990) Analysis of Panel Data. Cambridge: Cambridge University Press.

Judge, G. G., R. C. Hill, W. E. Giffiths, H. Lutkepohl and T. Lee (1982) Introduction to the Theory and Practice of Econometrics. New York: John Wiley \& Sons.

Keyfitz, N., and W. Flaeger (1990) World Population Growth and Aging: Demographic Trends in the Late Twentieth Century. Chicago: University of Chicago Press.

Krotki, K. J. (1985) Reported Masculinily Ratio in Pakistan: A Triumph of Anthropology and Economics over Biology. The Pakistan Development Review 24:3\&4 267-296.

Schultz, T. P. (1973) Explanation of Birth Rate Changes Overtime: A Study of Taiwan. JPE, Supplement 81: 238-274.

Simon, J. (1974) The Effects of Income on Fertility. Chapel Hill: Carolina Population Centre, University of North Carolina.

Summers, R., and A. Heston (1988) A New Set of International Comparisons of Real Product and Price Levels Estimates for 130 Countries, 1950-1985. Review of Income and Wealth 1-25.

Tafah-Edokat, E. O. (1992) Population Growth and Economic Development in a Developing Context: Problems and Policies. Artha Vijnana 34:2 155-62.

Ubaid-ur Rob, A. K. (1990) Socio-economic Determinants of Desired Fertility in Bangladesh. Demography India 19:2 251-261.

Wheeler, D. (1980) Human Resource Development and Economic Growth in Developing Countries. Washington, D. C.: World Bank. (World Bank Staff Working Paper 407.)

World Bank (Various Issues) World Development Report. Washington, D. C.: Oxford University Press. 